Obere Extremität 2018 · 13:45-61 https://doi.org/10.1007/s11678-018-0448-2 Published online: 22 February 2018 (c) The Author(s) 2018. This article is an open access publication.

CrossMark
This is an English translation of the publication Rehabilitation nach Rotatorenmanschettenrekonstruktion. Eine Arbeit der Kommission Rehabilitation der Deutschen Vereinigung für Schulter und Ellenbogenchirurgie e. V. (DVSE) in Zusammenarbeit mit dem Deutschen Verband für Physiotherapie (ZVK) e. V., dem Verband Physikalische Therapie, Vereinigung für die physiotherapeutischen Berufe (VPT) e. V. und der Sektion Rehabilitation-Physikalische Therapie der Deutschen Gesellschaft für Orthopädie und Unfallchirurgie e. V. (DGOU) Obere Extremität 2016, 11:16-31 DOI https://doi.org/10.1007/s11678-0150346-9.

Christian Jung ${ }^{1}$ Lena Tepohl ${ }^{2} \cdot$ Reina Tholen $^{3} \cdot$ Knut Beitzel $^{4} \cdot$ Stefan Buchmann ${ }^{4,5}$. Thomas Gottfried ${ }^{6,14}$. Casper Grim ${ }^{7}$ • Bettina Mauch ${ }^{8}$. Gert Krischak ${ }^{2,9,14}$. Hans Ortmann ${ }^{10} \cdot$ Christian Schoch $^{11} \cdot$ Frieder Mauch $^{12,13}$

'Schulthess Klinik Zürich, Obere Extremitäten, Zürich, Switzerland

${ }^{2}$ Institut für Rehabilitationsmedizinische Forschung an der Universität Ulm, Bad Buchau, Germany

${ }^{3}$ Deutscher Verband für Physiotherapie (ZVK) e. V., Köln, Germany

${ }^{4}$ Abteilung und Poliklinik für Sportorthopädie, Klinikum rechts der Isar, München, Germany

${ }^{5}$ Orthopädisches Fachzentrum (OFZ), Weilheim i. Obb., Germany

${ }^{6}$ Klinik Hoehenried gGmbH der Deutschen Rentenversicherung Bayern Sued, Bernried, Germany

${ }^{7}$ Klinikum Osnabrück GmbH, Osnabrück, Germany

${ }^{8}$ Klinikum Stuttgart-Bad Cannstatt, Stuttgart, Germany

${ }^{9}$ Federseeklinik Bad Buchau, Bad Buchau, Germany

${ }^{10}$ Verband Physikalische Therapie (VPT) e. V. Landesgruppe Bayern, München, Germany

"St. Vinzenz Allgäu, Pfronten, Germany

${ }^{12}$ Sportklinik Stuttgart, Stuttgart, Germany

${ }^{13}$ Kommission Rehabilitation der Deutschen Vereinigung für Schulter und Ellenbogenchirurgie e. V. (DVSE), Stuttgart, Germany

${ }^{14}$ Sektion Rehabilitation - Physikalische Therapie der Deutschen Gesellschaft fuer Orthopaedie und Unfallchirurgie e. V. (DGOU), Berlin, Germany

\title{
Rehabilitation following rotator cuff repair
}

\author{
A work of the Commission Rehabilitation of \\ the German Society of Shoulder and Elbow \\ Surgery e. V. (DVSE) in collaboration with the \\ German Association for Physiotherapy (ZVK) \\ e. V., the Association Physical Therapy, Asso- \\ ciation for Physical Professions (VPT) e. V. \\ and the Section Rehabilitation-Physical \\ Therapy of the German Society for \\ Orthopaedics and Trauma e. V. (DGOU)
}

\section{Introduction}

Tears of the rotator cuff tendons (RC) are a frequent cause of shoulder complaints [44]. Improvement in terms of strength, movement and pain reduction can be expected after rotator cuff repair surgery [27]. Unfortunately, there is no consensus on the rehabilitation protocols and contents following the surgical procedure [24]. Conventional rehabilitation protocols after reconstruction of the rotator cuff (RCR) often vary considerably, even in terms of basic content such as the length of immobilization, movement limitations and whether or not an orthosis should be used. There still is a lack of evidence for many common forms of rehabilitation contents, although in many health care systems evidence-based medicine has gained ground. In Germany, among others, the guideline program of the German Pension Insurance Association focused on this conflict [23, 25]. 


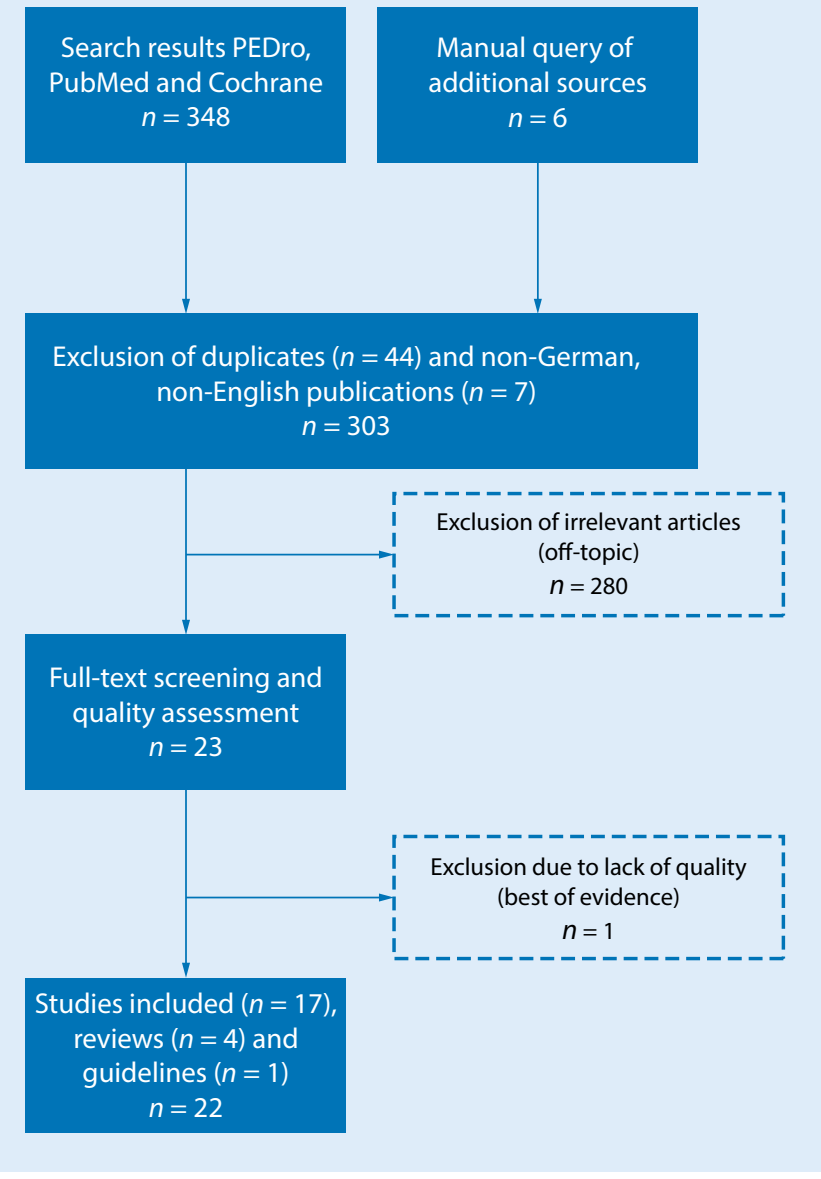

Fig. $1<$ Systematic review search algorithm
The rehabilitation commission of the German Society for Shoulder and Elbow Surgery (DVSE) has studied this issue intensively. The aim of this paper was, firstly, to conduct an evidence-based evaluation of the most important forms of treatment after RCR, based on an extensive literature review and, with the help of a survey among DVSE shoulder experts, to determine if there is an existing bestclinical practice consensus for or against specific forms of treatment.

\section{Materials and methods}

\section{Literature review}

The literature search had a hierarchical structure (best available evidence) based on guidelines, health technology assessments (HTA), systematic reviews and clinical studies that investigated postoperative rehabilitation after RCR. This was supplemented by an analysis of the primary literature under examination
(• Fig. 1). We started by searching for national and international guidelines in the databases of the "Guidelines International Network" (http://www.g-i-n.net/), various other national guidelines (National Guideline Clearinghouse, AWMF, SIGN, NICE) and HTA (INAHTA, HTAi, EUnetHTA, DIMDI, IQWiG).

A search for meta analyses, systematic reviews and primary studies was conducted using the electronic databases Medline via PubMed, the Cochrane Central Register of Controlled Trials, the Cochrane Database of Systematic Reviews and the Physiotherapy Evidence Database (PEDro). The period between $1 / 2004$ and 10/2014 was the period of reference. In addition, a manual search was conducted that included general internet research, a screening of the literature references listed in the collected articles, and a renewed assessment of various journals. A manual search for relevant animal studies was also performed for the topics of tendon healing and length of immobilization. The relevant publications were selected based on how relevant their content was to the issue, whether they were in English or German, and whether the comparative studies enlisted at least ten patients per group.

The literature was selected based on the PICO concept of the Cochrane Institute (-Table 1). The levels of evidence were interpreted based on the classifications of the Oxford Center for EvidenceBased Medicine 2009 (OCEBM).

The PEDro scale (http://www.pedro. org.au) was used to analyze the individual studies and the systematic reviews were assessed according to AMSTAR (assessment of multiple systematic reviews; http://amstar.ca). Only studies that demonstrated the highest obtainable level of evidence served as the basis for the consensus paper. At least two studies were required per topic. For example, if there was only one Level I study done on the topic, Level II studies were also taken into account. If there were two or more Level I studies, no Level II, III and IV studies were considered. Consensus topics that were not presented accordingly in the literature were included on the basis of "best available evidence".

\section{Expert opinions}

After evaluating the literature, the DVSE's Rehabilitation Commission decided which topics required the opinions of the DVSE experts. The individual topics were assigned to the following groups:

1. Immobilization and arm positioning

2. Physical therapy (cryotherapy, electrotherapy, hydrotherapy)

3. Physiotherapy, self-exercise and CPM (continuous passive motion)

\section{Rehabilitation protocols}

The online tool Surveymonkey (www. surveymonkey.com) was used to survey 63 selected DVSE experts between 2/2015 and $4 / 2015$. The participation rate was $69.8 \%$. 


\section{Results and discussion}

The guideline search resulted in one hit for the American Academy of Orthopedic Surgeons. Two systematic reviews and 13 clinical studies in the databases were examined. A manual search revealed two additional systematic reviews and four individual studies. An overview of all the papers is listed in $\bullet$ Tables 2, 3 and 4 .

In order to do justice to the amount of information contained in each publication, the individual sub-topics of the overall rehabilitation process are thematically assessed and discussed in individual sub-sections below. Furthermore, the results of the expert survey are presented according to topic.

\section{Immobilization and arm positioning}

Directly after the operation, the question arises as to whether and to what extent the shoulder should be immobilized. The risk of a re-rupture or disrupted tendon healing as a result of too much strain have to be weighed against a stiff shoulder caused by too little mobilization. Cadaver studies reveal that the so-called "time zero strength" of the sutured supraspinatus tendon resists $70-100 \%$ of the forces affecting it [40]. However, biomechanical studies have shown there is a "gapping effect" for cyclical, clinically relevant strain, even in the case of double row suture techniques [40]. As tendon healing progresses, the biomechanical properties of the tendon-suture-construct change. Therefore, the time it takes for tendons to heal should be taken into account. Animal studies are frequently referred to, since the tendon healing process has already been intensively studied in animals. In animal models a fragile scar appears 0-14 days after the operation during the inflammatory phase [7]. In the subsequent proliferative phase, 3-4 weeks after the operation, fibroblasts, myofibroblasts and endothelial cells appear, neoangiogenesis begins, and a stronger tendonbone connection develops. In the maturation and remodeling phase, starting in weeks 4 to 6 , collagen III is increasingly replaced by mature collagen I and

Obere Extremität 2018 · 13:45-61 https://doi.org/10.1007/s11678-018-0448-2

(c) The Author(s) 2018. This article is an open access publication.

\section{Jung · L. Tepohl · R. Tholen · K. Beitzel · S. Buchmann · T. Gottfried · C. Grim • B. Mauch • G. Krischak · H. Ortmann · C. Schoch · F. Mauch}

Rehabilitation following rotator cuff repair. A work of the Commission Rehabilitation of the German Society of Shoulder and Elbow Surgery e. V. (DVSE) in collaboration with the German Association for Physiotherapy (ZVK) e. V., the Association Physical Therapy, Association for Physical Professions (VPT) e.V. and the Section Rehabilitation-Physical Therapy of the German Society for Orthopaedics and Trauma e. V. (DGOU)

\section{Abstract}

Background. Tears and lesions of the rotator cuff are a frequent cause of shoulder pain and disability. Surgical repair of the rotator cuff is a valuable procedure to improve shoulder function and decrease pain. However, there is no consensus concerning the rehabilitation protocol following surgery.

Objectives. To review and evaluate current rehabilitation contents and protocols after rotator cuff repair by reviewing the existing scientific literature and providing an overview of the clinical practice of selected German Society of Shoulder and Elbow Surgery e. V. (DVSE) shoulder experts.

Materials and methods. A literature search for the years 2004-2014 was conducted in relevant databases and bibliographies including the Guidelines International
Network, National Guidelines, PubMed, Cochrane Central

Register of Controlled Trials, Cochrane Database of Systematic Reviews, and the Physiotherapy Evidence Database. In addition, 63 DVSE experts were contacted via online questionnaire.

Results. A total of 17 studies, four reviews and one guideline fulfilled the inclusion criteria. Based on these results and the obtained expert opinions, a four-phase rehabilitation protocol could be developed.

\section{Keywords}

Treatment outcome Rotator cuff repair - Tendon reconstruction - Cuff tear . Physiotherapy the tendon integrates more strongly and stably into the bone.

Animal studies have shown that the time it takes to achieve full strength varies between 12 and 26 months [7]. When the issue of early exercise therapy is translated to animal models, difficulties arise in comparing and interpreting the different animal models. It is also difficult to standardize any exercises for animals. Transferring the findings to humans also poses a challenge.

Li et al. [30] found that early passive exercise benefited tendon healing in rabbits. Peltz et al. [36] demonstrated in a rat model that movement was poorer when there was passive exercise directly after the operation as a result of increased scar formation. There were no differences with respect to tendon healing. By contrast, Gimbel et al. [16] found in rat models that the healing tendon had better mechanical properties when immobilization was extended. However, it is interesting to note that complete strain reduction using a botulinum toxin appears to have negative effects on tendon recovery in animal models [13]. In a comparison study of rabbits that compared immediately allowing movement, short-term immobilization with subsequent passive exercise and complete immobilization [47] Zhang et al. found that direct, postoperative passive exercise with intermittent immobilization did not negatively affect tendon healing histologically and in magnetic resonance imaging (MRI). However, tendon healing was found to diminish when function was completely allowed.

Compared to these heterogeneous animal studies, prospective studies of humans provide a good level of data. Early passive exercise does not appear to be disadvantageous [19]. Both Chan et al. [6] and Shen et al. [41] were able to show in meta analyses of randomized clinical comparative studies that no significant differences can be expected in the clinical outcome and in terms of the re- 


\section{Table 1 PICO-System (Cochrane Institute)}

P Population Patients in post operative rehabilitation after rotator cuff repair

I Intervention Specific treatment modalities during post operative rehabilitation after rotator cuff repair (e. g. frequency, duration and interval of therapy)

C Comparison Patients without specific treatment modalities during post operative rehabilitation after rotator cuff repair

O Outcome Impact of treatment modalities during post operative rehabilitation after rotator cuff repair (e. g. improvement of function, pain or quality of life)

Table 2 Search results reviews

\begin{tabular}{|c|c|c|c|c|c|}
\hline Author & Year & Title & $\begin{array}{l}\text { Level of } \\
\text { Evidence }\end{array}$ & Studies & Outcome-Measure \\
\hline $\begin{array}{l}\text { Chan } \\
\text { et al }\end{array}$ & 2014 & $\begin{array}{l}\text { Delayed versus } \\
\text { early motion } \\
\text { after arthro- } \\
\text { scopic rotator } \\
\text { cuff repair: } \\
\text { a meta-analysis }\end{array}$ & $\begin{array}{l}\text { Review } \\
1 \mathrm{~A} / 1+\end{array}$ & 3 & $\begin{array}{l}\text { Primary outcome: functional } \\
\text { scores from the validated ASES } \\
\text { scale } \\
\text { Secondary outcome: Constant- } \\
\text { Murley scale (CMS), Simple } \\
\text { Shoulder Test (SST), Western } \\
\text { Ontario Rotator Cuff (WORC) } \\
\text { index, and Disabilities of the } \\
\text { Arm, Shoulder, and Hand } \\
\text { (DASH) }\end{array}$ \\
\hline $\begin{array}{l}\text { Shen } \\
\text { et al }\end{array}$ & 2014 & $\begin{array}{l}\text { Does immobi- } \\
\text { lization after } \\
\text { arthroscopic } \\
\text { rotator cuff } \\
\text { repair increase } \\
\text { tendon healing? } \\
\text { A systematic } \\
\text { review and } \\
\text { meta-analysis }\end{array}$ & $\begin{array}{l}\text { Review } \\
1 \mathrm{~A} / 1+\end{array}$ & 3 & $\begin{array}{l}\text { Primary outcome: tendon } \\
\text { healing in the repaired cuff } \\
\text { Secondary outcome: range of } \\
\text { motion (ROM) and American } \\
\text { Shoulder and Elbow Surgeons } \\
\text { (ASES) shoulder scale, Simple } \\
\text { Shoulder Test (SST), Constant, } \\
\text { and visual analog scale (VAS) } \\
\text { for pain scores }\end{array}$ \\
\hline
\end{tabular}

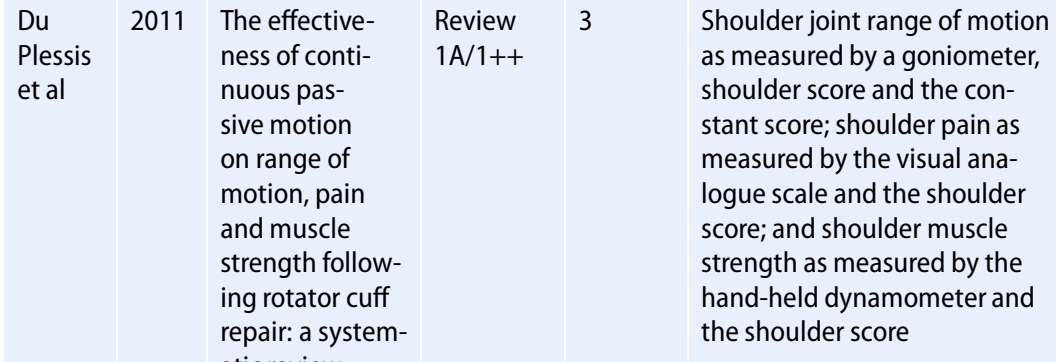

atic review

Baum- 2009 Rotator cuff Review 4

$\begin{array}{lll}\text { garten } & \text { repair rehabili- } & 1 \mathrm{~A} / 1+\end{array}$

et al tation: a level I and II systematic review

\section{Result/Conclusion}

Three level I and 1 level II randomized trials were eligible and included. Pooled analysis revealed no statistically significant differences in American Shoulder and Elbow Surgeons scores between delayed vs early motion rehabilitation (mean difference [MD], $1.4 ; 95 \%$ confidence interval $[\mathrm{Cl}],-1.8$ to $4.7 ; P=0.38$, $I(2)=34 \%)$. The risk of retears after surgery did not differ statistically between treatment groups (risk ratio, $1.01 ; 95 \% \mathrm{Cl}, 0.63-1.64 ; P=0.95)$. Early passive motion led to a statistically significant, although clinically unimportant, improvement in forward elevation between groups $\left(\mathrm{MD},-1^{\circ} ; 95 \% \mathrm{Cl},-2^{\circ}\right.$ to $0^{\circ} ; P=0.04$, $\mathrm{I}(2)=0 \%)$. There was no difference in external rotation between treatment groups $\left(\mathrm{MD}, 1^{\circ} ; 95 \% \mathrm{Cl},-2^{\circ}\right.$ to $\left.4^{\circ} ; P=0.63, I(2)=0 \%\right)$. None of the included studies identified any cases of postoperative shoulder stiffness Three randomized controlled trials (RCTs) examining 265 patients were included. Meta-analysis revealed no significant difference in tendon healing in the repaired cuff between the early-motion and immobilization groups. A significant difference in external rotation at 6 months postoperatively favored early motion over immobilization, but no significant difference was observed at 1 year postoperatively. In one study, Constant scores were slightly higher in the early-motion group than in the immobilization group. Two studies found no significant difference in ASES, SST, or VAS score between groups

Continuous passive motion is safe to use with physiotherapy treatment following rotator cuff repair surgery. It may help to prevent secondary complications post operatively

Two studies examined the use of continuous passive motion for rotator cuff rehabilitation, and 2 studies compared an unsupervised, standardized rehabilitation program to a supervised, individualized rehabilitation program. These studies did not support the use of continuous passive motion in rotator cuff rehabilitation, and no advantage was shown with a supervised, individualized rehabilitation protocol compared to an unsupervised, standardized home program. Each investigation had weaknesses in study design that decreased the validity of its findings 


\begin{tabular}{|l|l|l|}
\hline Editor & Year & Title \\
\hline $\begin{array}{l}\text { American Academy } \\
\text { of Orthopaedic } \\
\text { Surgeons (AAOS) }\end{array}$ & 2010 & $\begin{array}{l}\text { Optimizing the } \\
\text { Management of } \\
\text { Rotator Cuff Prob- } \\
\text { lems-Guideline } \\
\text { and Evidence } \\
\text { Report }\end{array}$ \\
\hline
\end{tabular}

\section{Recommendation \& Statement}

Post-Operative Treatment-Cold Therapy

In the absence of reliable evidence, it is the opinion of the work group that local cold therapy is Beneficial to relieve pain after rotator cuff surgery. Strength of Recommendation: Consensus

Post-Operative-Sling, shoulder immobilizer, abduction pillow, or abduction brace We cannot recommend for or against the preferential use of an abduction pillow versus a standard sling after rotator cuff repair. Strength of Recommendation: Inconclusive

Post-Operative Rehabilitation-Range of Motion Exercises

We cannot recommend for or against a specific time frame of shoulder immobilization without range of motion exercises after rotator cuff repair. Strength of Recommendation: Inconclusive

\section{Post-Operative Rehabilitation-Active Resistance Exercises}

We cannot recommend for or against a specific time interval prior to initiation of active resistance exercises after rotator cuff repair. Strength of Recommendation: Inconclusive

Post-Operative Rehabilitation-Home Based Exercise and Facility Based Rehabilitation We cannot recommend for or against home-based exercise programs versus facility-based rehabilitation after rotator cuff surgery. Strength of Recommendation: Inconclusive

Post-Operative-Infusion Catheters

We cannot recommend for or against the use of an indwelling subacromial infusion catheter for pain management after rotator cuff repair. Strength of Recommendation: Inconclusive

rupture rate. When there is early passive exercise, the full range of motion (ROM) is also achieved more quickly, particularly in terms of flexion. In a detailed evaluation of the meta analyses and our own additional review of the literature, a total of four Level I studies were identified that support the recommendation of early passive mobilization [2, 8, 20, 22].

By contrast, early aggressive active exercise should be avoided since this negatively impacts the healing process [20]. In order to protect patients from excessive strain outside the therapy setting, an aid can be used to immobilize the arm. Based on the timeframe of tendon healing mentioned above, the length of immobilization varies widely between 4 and 8 weeks $[2,4,14,21,22,29]$. There are no prospective studies that deal only with the length of immobilization.

While the duration of immobilization is the subject of debate, immobilization in slight abduction is predominantly preferred by the experts surveyed as this increases blood circulation in the tendon and reduces the strain on the reconstruction [38]. Gerber et al. [15] and Thomopoulos et al. [45] were also able to show in animal models that a position that lowers the strain on the tendon reconstruction has a positive effect on the orientation of the collagen fibers and the elasticity of the tendon. Orthoses are, in principle, suitable for lowering the activity of the RC muscles. This was proven by
Alenabi et al. [1] in an electromyographic study. When the elbow and hand were moved in a splint, the activity of the RC muscle was measured at no more than $10 \%$ of normal activity. There are no clinical investigations that specifically look at the type of orthoses used. The German catalog of medical aids allows both the use of arm slings and abduction pillows with a varying abduction of $15-45^{\circ}$ for post-treatment after an RCR.

\section{Conclusions}

Early passive, postoperative exercise can be used without indicating an increased rate of disruption of the healing process or ruptures. Employing an orthosis can protect against active strain that is applied too early. There are no evidence-based recommendations regarding the length of time that postoperative immobilization should last. The use of an arm abduction pillow can be considered (see 0 Table 5 for DVSE expert opinions on immobilization).

\section{Physical therapy}

Cryotherapy, electrotherapy and exercise in an exercise pool are frequent methods of physical therapy that are used following an RCR. In a randomized clinical trial (RCT) with 50 patients conducted in 1996, Speer et al. [43] investigated the effects of using cryotherapy systems after a variety of shoulder operations, including RCR. Continuous cryotherapy leads to a reduction in pain, a reduced need for pain killers and better sleep quality in the night after the operation. When cryotherapy was used (4 to 6 times per day depending on patient requirements) there was less pain when the arm was at rest and in motion in the 10 days following the operation. In another RCT, the same working group also observed clinically relevant effects on pain in the cryotherapy group when at rest and when physical strain was placed on the shoulder following open and arthroscopic shoulderoperations ( $n=70$; water temperature $7-13^{\circ} \mathrm{C}$; length it was worn: continuously $48 \mathrm{~h}$ postoperatively; at night on days $3-7$; daily $2-4 \mathrm{~h}$ on days $8-21$ followed by exercise therapy; [42]). Speer's group also demonstrated that continuous cryotherapy directly following reconstruction of the $\mathrm{RC}$ reduced the temperature in the glenohumeral joint and subacromial space by around $0.5-1.0^{\circ} \mathrm{C}$ [35].

Blum et al. [4] compared two types of electrotherapy in an RCT with 22 patients who received $\mathrm{RC}$ reconstruction. The control group received $2 \times 1 \mathrm{~h}$ of electrotherapy per day in connection with physiotherapy that started 6-8 weeks post-op. The intervention group received the same length of sham electrotherapy and physiotherapy that began 8 weeks after the operation. 


\section{Review}

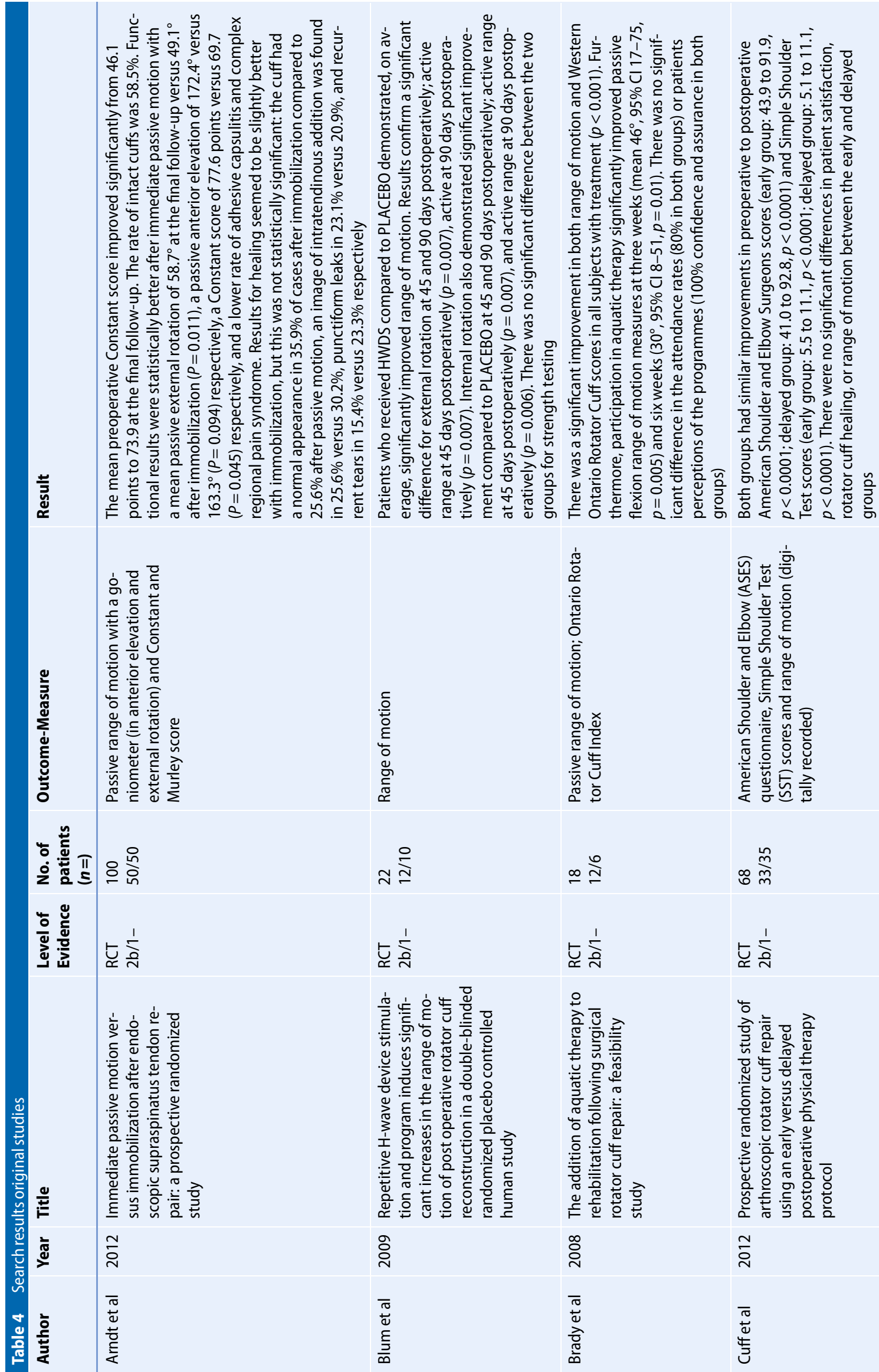




\begin{tabular}{|c|c|c|c|c|c|c|}
\hline 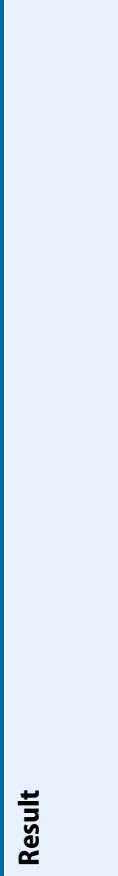 & 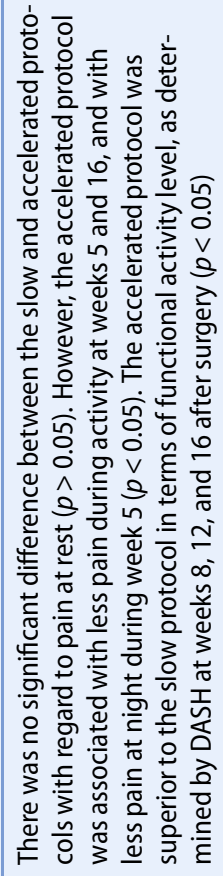 & 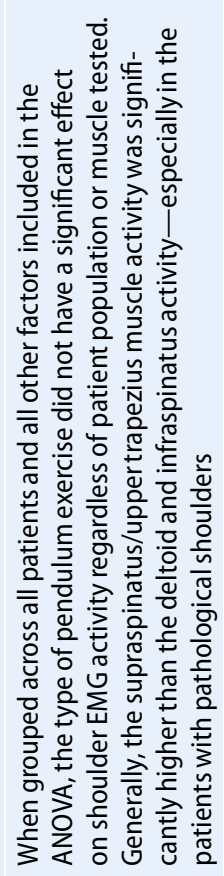 & 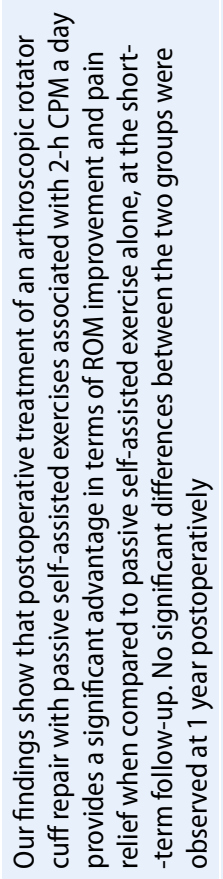 & 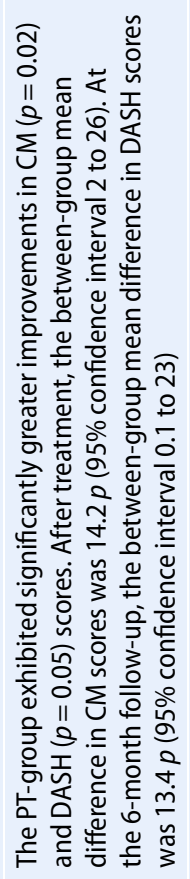 & 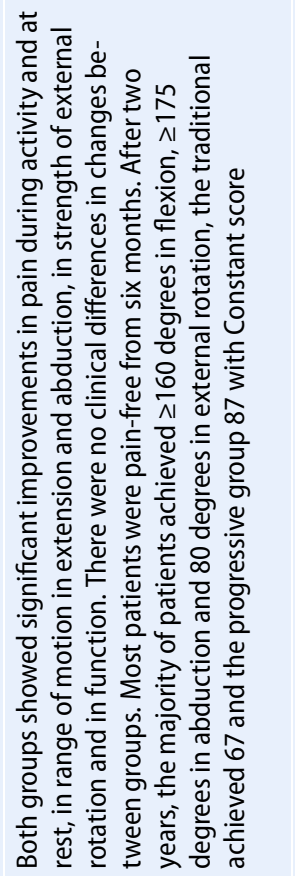 & 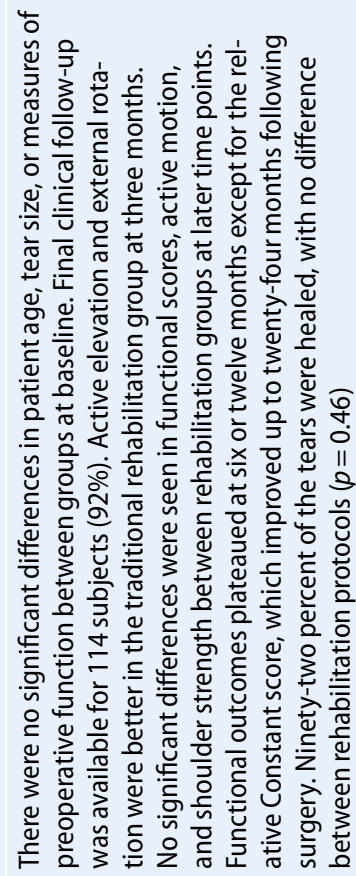 \\
\hline 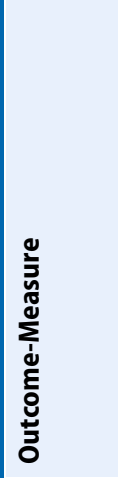 & 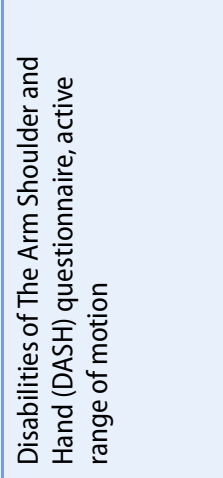 & 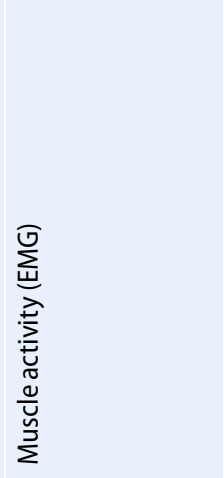 & 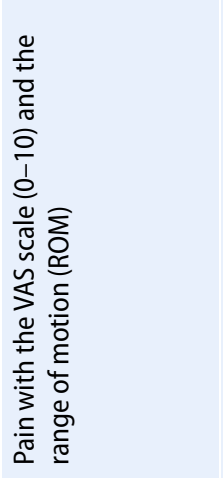 & 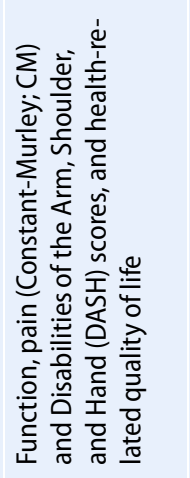 & 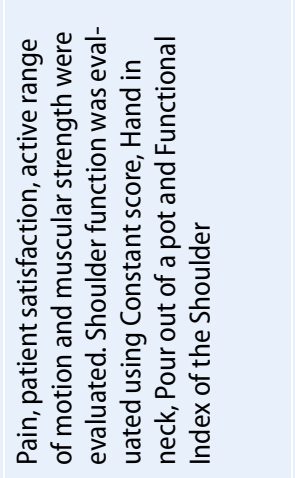 & 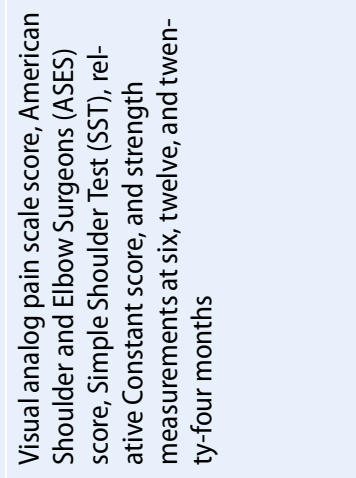 \\
\hline 范 & શ $\stackrel{\circ}{\frac{m}{m}}$ & ¿ & ○ $\frac{0}{\dot{y}}$ & $\stackrel{\stackrel{\infty}{\infty}}{\stackrel{\infty}{-}}$ & ষ & 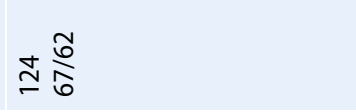 \\
\hline 屯ั & ঢ $\frac{1}{\frac{1}{n}}$ & d心 & ヒ 을 & ঢ $\frac{1}{\frac{1}{2}}$ & 议 $\frac{1}{\frac{1}{N}}$ & ヒ⿺ 丶 $\frac{1}{\frac{1}{N}}$ \\
\hline$\frac{0}{E}$ & 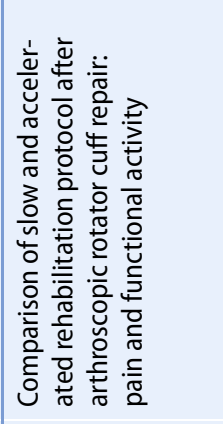 & 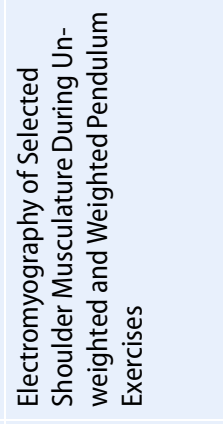 & 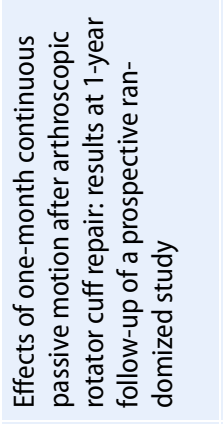 & 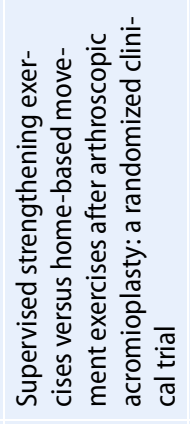 & 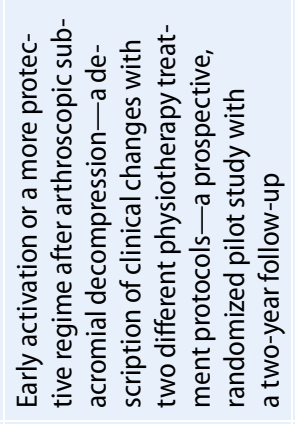 & 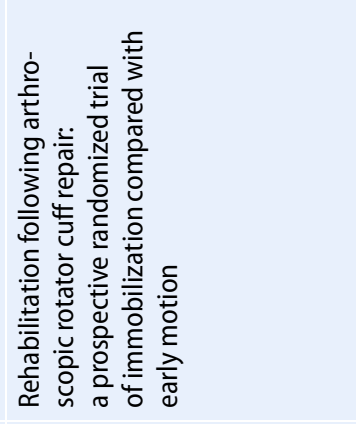 \\
\hline ঠ & $\bar{i}$ & ஜ্ণ & 윰 & $\stackrel{\sim}{ָ}$ & 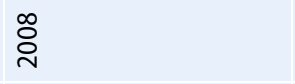 & ¿্ঠ \\
\hline 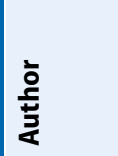 & 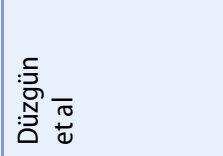 & 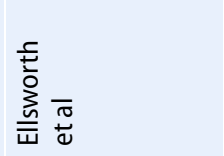 & 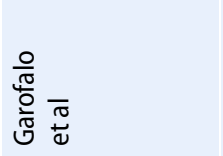 & 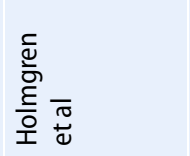 & 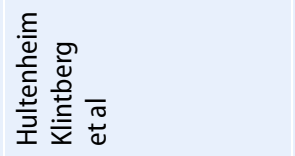 & 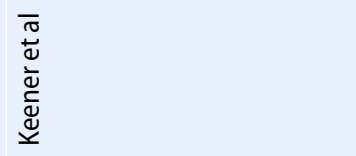 \\
\hline
\end{tabular}




\section{Review}

\begin{tabular}{|c|c|c|c|c|}
\hline 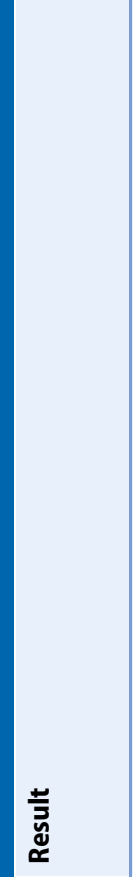 & 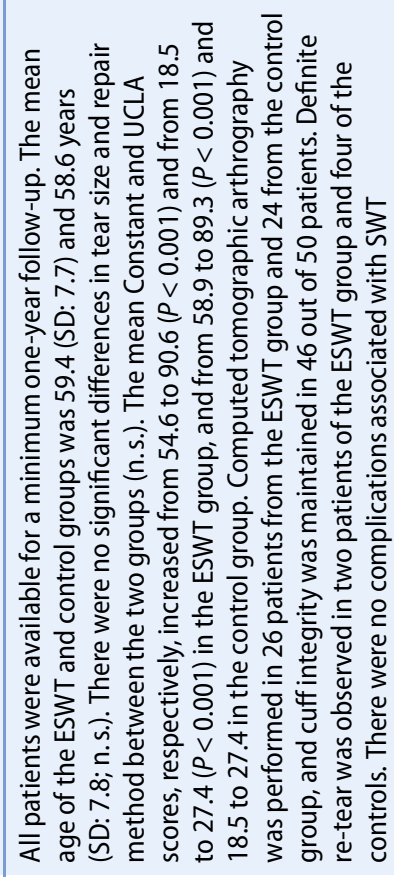 & 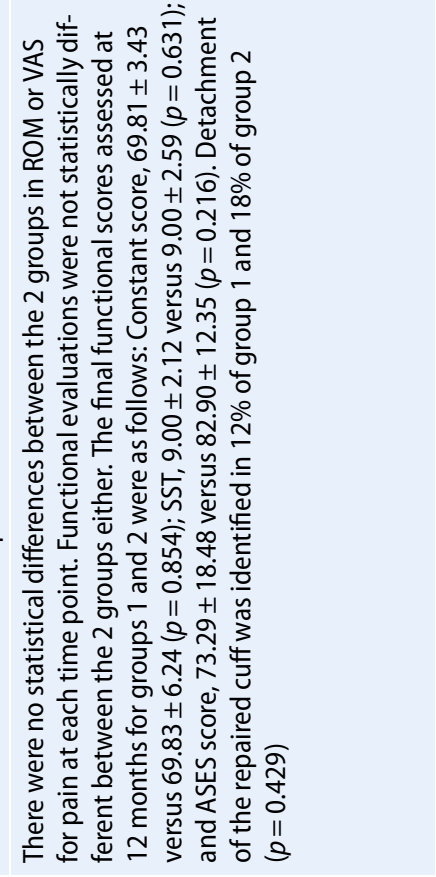 & 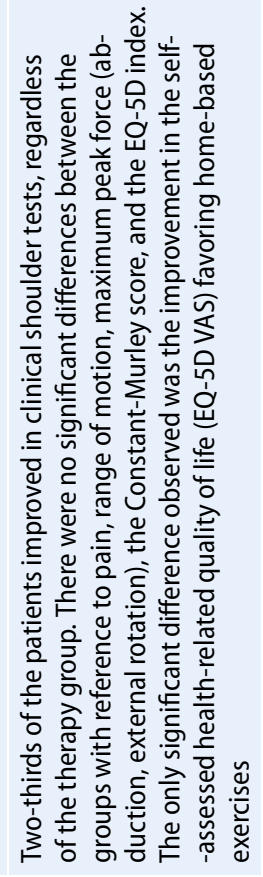 & 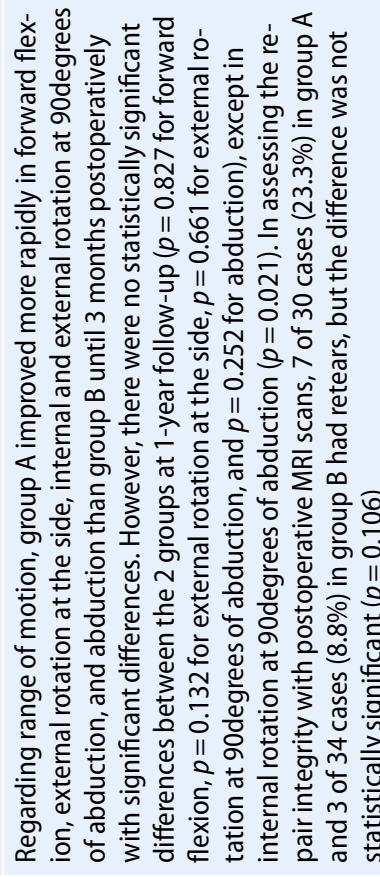 \\
\hline 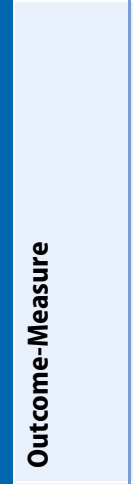 & 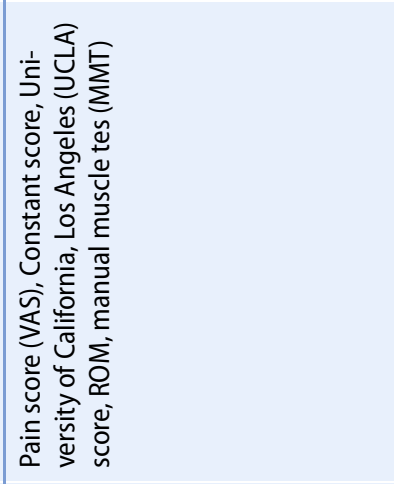 & 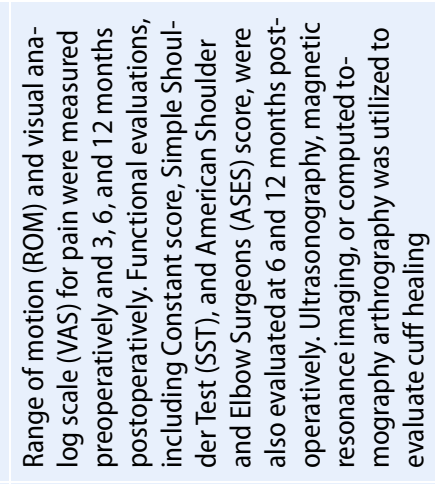 & 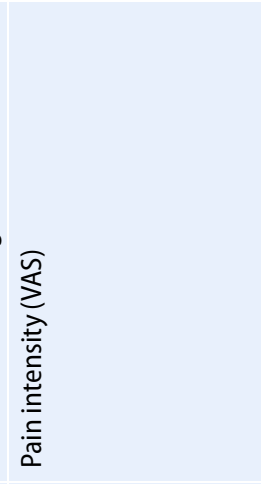 & 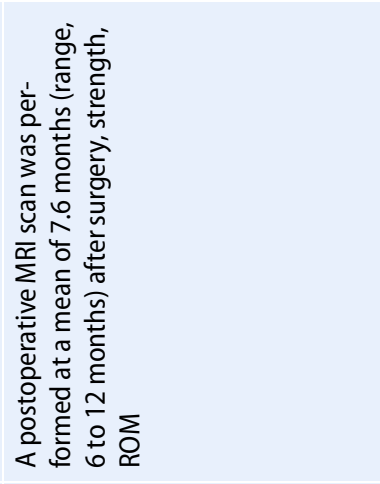 \\
\hline ¿t & 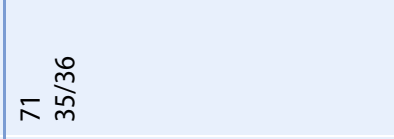 & $\cong \hat{n}$ & 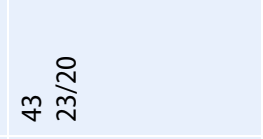 & $\omega \underset{\infty}{\stackrel{\mathcal{F}}{\tilde{F}}}$ \\
\hline 苋 & 노 $\frac{1}{\frac{1}{a}}$ & 낭 $\frac{1}{2}$ & 누 $\frac{1}{\frac{1}{d}}$ & $t \underset{\propto}{\stackrel{1}{a}}$ \\
\hline$\vdash$ & 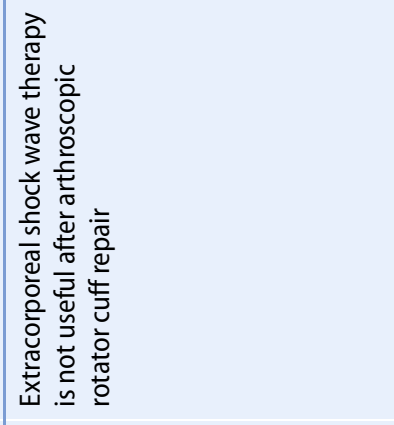 & 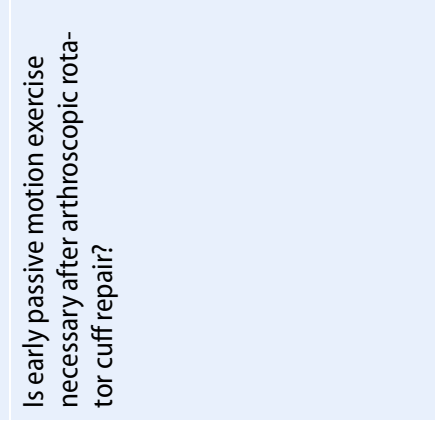 & 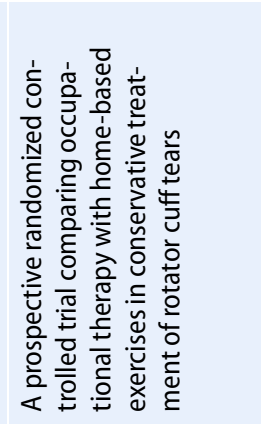 & 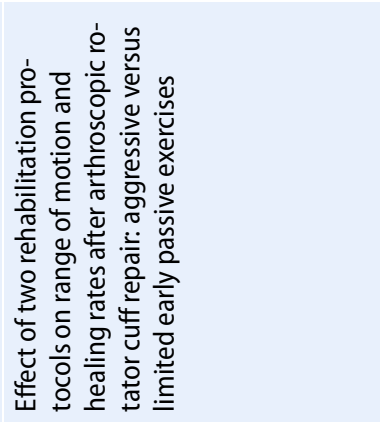 \\
\hline む్ & $\stackrel{\sim}{\grave{2}}$ & $\stackrel{\sim}{\tilde{\nu}}$ & $\dot{m}_{i}^{n}$ & $\stackrel{\sim}{\check{N}}$ \\
\hline 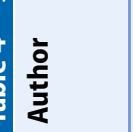 & 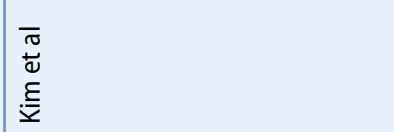 & $\begin{array}{l}\bar{\pi} \\
\stackrel{0}{ \pm} \\
\stackrel{y}{y}\end{array}$ & 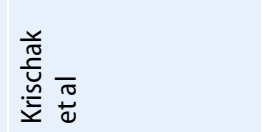 & $\begin{array}{l}\bar{\sigma} \\
\stackrel{\Delta}{0} \\
\Xi \\
\Xi\end{array}$ \\
\hline
\end{tabular}




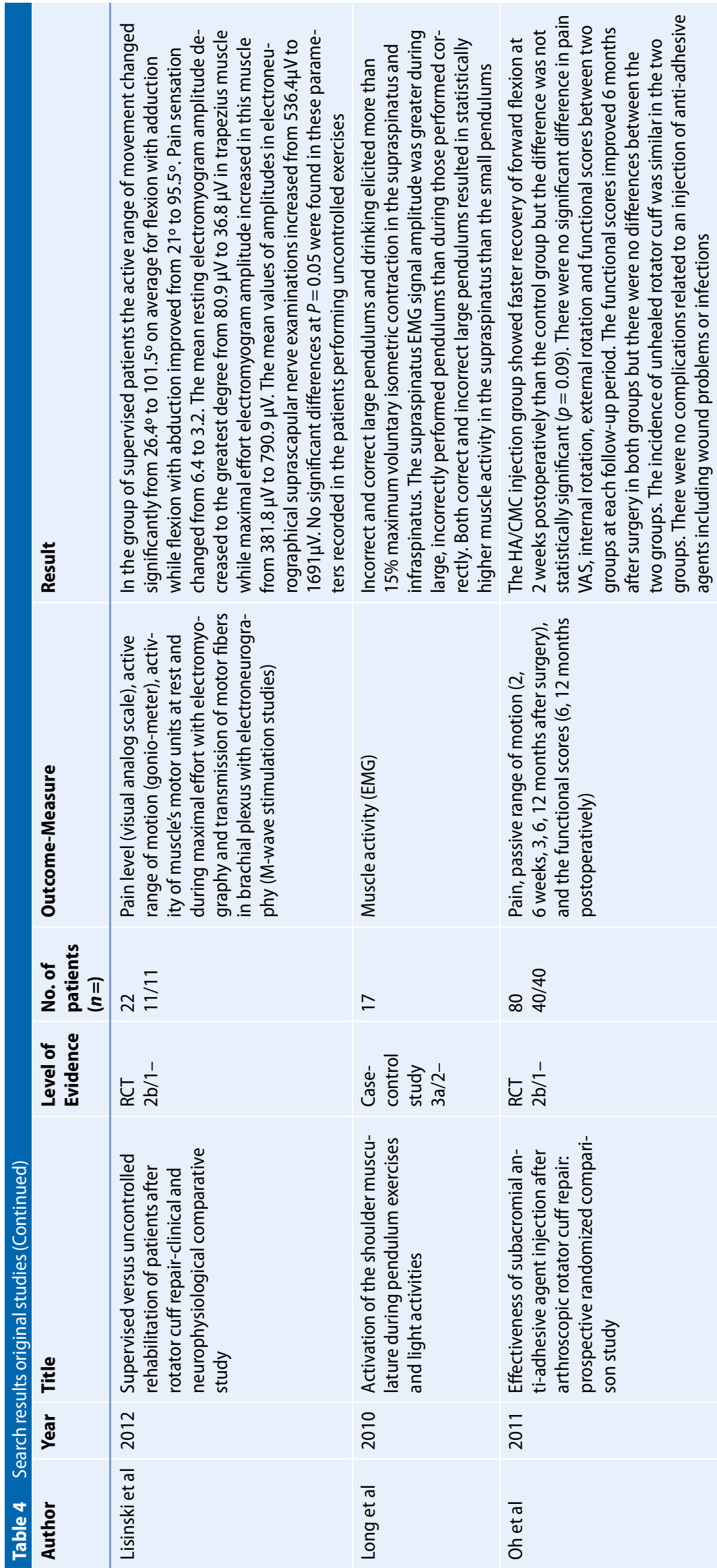

In contrast to the control group, movement improved in the intervention group by around $10^{\circ} 45$ and 90 days after the operation, however strength did not. The methodological quality of the study should be regarded critically as the authors had a relevant conflict of interest.

A non-randomized study indicates that additional group sessions of aquatic theraphy (starting 10 days after reconstruction) have a positive effect on passive movement (anteversion and external rotation), pain and activities of daily living (Western Ontario Rotator Cuff Score) 3 and 6 weeks, though not 12 weeks, post operation [5]. However, the effects were slight and could also be the result of an overall higher amount of active intervention in the aquatic therapy group.

\section{Conclusions}

Cryotherapy is recommended in the first 3 weeks following RCR in order to support rehabilitation and, in particular, to treat pain [43]. Based on current published studies, no clear recommendation can be made for or against electrotherapy, aquatic therapy, the application of heat, massages, therapeutic ultrasound, extracorporeal shockwave therapy and injections of hyaluronic acid $[4,5,21$, 34].

Individual studies indicate a potential benefit of electrotherapy and group training in an exercise pool (see - Table 6 for DVSE expert opinions on physical therapy).

\section{Continuous passive motion}

Continuous passive motion therapy with a motorized CPM machine is one of the most frequently used elements of treatment following an operation on a shoulder joint, and particularly after RCR. The passive motion machine typically serves to mobilize the joint shortly after the operation without the patient having to actively support the extension of motion.

Currently scientific literature only contains two reviews $[3,10]$ and one prospective randomized study [14]. The review by Baumgarten et al. [3] is based 


\begin{tabular}{|c|c|c|c|c|}
\hline & $\begin{array}{l}\text { Appropriate } \\
(\%)\end{array}$ & $\begin{array}{l}\text { Rather ap- } \\
\text { propriate } \\
\text { (\%) }\end{array}$ & $\begin{array}{l}\text { Rather not } \\
\text { appropriate } \\
(\%)\end{array}$ & $\begin{array}{l}\text { Not appropriate } \\
\text { (\%) }\end{array}$ \\
\hline $\begin{array}{l}\text { Question 1: } \\
\text { After a RCR, the operated shoulder should be immobilized for } \\
4-6 \text { weeks, i. e. neither treated passively nor actively. } \\
\text { I consider this statement to be: }\end{array}$ & 9.1 & 9.1 & 11.4 & 70.5 \\
\hline $\begin{array}{l}\text { Question 2: } \\
\text { I think early passive exercise of the shoulder after RCR is beneficial. } \\
\text { I consider this statement to be: }\end{array}$ & 63.6 & 22.7 & 9.1 & 4.5 \\
\hline $\begin{array}{l}\text { Question 3: } \\
\text { I fear a relevant stiffening of the shoulder, if it is completely }{ }^{\mathrm{b}} \text { immo- } \\
\text { bilized for the first } 4-6 \text { weeks after RCR. } \\
\text { I consider this statement to be: }\end{array}$ & 38.6 & 34.1 & 22.7 & 4.5 \\
\hline Question 4: & 6.8 & 13.6 & 34.1 & 45.5 \\
\hline & No device & Sling & $\begin{array}{l}\text { Brace } \\
(\text { Abd:15-20) }\end{array}$ & $\begin{array}{l}\text { Brace } \\
\left(\text { Abd: }>20^{\circ}\right)\end{array}$ \\
\hline $\begin{array}{l}\text { Question 5: } \\
\text { Do you recommend any kind of orthopedic orthosis, brace or sling } \\
\text { after RCR, and if so, which one? }\end{array}$ & 2.3 & 27.9 & 69.8 & 11.6 \\
\hline $\begin{array}{l}\text { Question 6: } \\
\text { What is the timeframe an orthosis/brace/sling should be worn? }\end{array}$ & \multicolumn{4}{|c|}{ Min.: 1w-Max.: 12w; Ø: 4.9w; Median: 6w } \\
\hline
\end{tabular}

\section{Table 6 DVSE experts survey —Physical therapy (no. of responds $n=44$ )}

\begin{tabular}{|c|c|c|c|c|}
\hline & $\begin{array}{l}\text { Appropriate } \\
\text { (\%) }\end{array}$ & $\begin{array}{l}\text { Rather ap- } \\
\text { propriate } \\
(\%)\end{array}$ & $\begin{array}{l}\text { Rather not } \\
\text { appropri- } \\
\text { ate (\%) }\end{array}$ & $\begin{array}{l}\text { Not ap- } \\
\text { propriate } \\
(\%)\end{array}$ \\
\hline $\begin{array}{l}\text { Question } 1 \text { : } \\
\text { The use of cryotherapy to reduce } \\
\text { pain after a RCR is reasonable. } \\
\text { I consider this statement to be: }\end{array}$ & 36.4 & 40.9 & 18.2 & 4.5 \\
\hline $\begin{array}{l}\text { Question 2: } \\
\text { Electrotherapy plays a relevant role } \\
\text { in the post-operative treatment } \\
\text { after RCR. } \\
\text { I consider this statement to be: }\end{array}$ & 6.8 & 13.6 & 40.9 & 38.6 \\
\hline $\begin{array}{l}\text { Question 3: } \\
\text { Assisted active exercises as part of } \\
\text { aquatic therapy (e.g. in a training } \\
\text { pool) can improve active mobility } \\
\text { after a RCR. } \\
\text { I consider this statement to be: }\end{array}$ & 45.5 & 36.4 & 15.9 & 2.3 \\
\hline
\end{tabular}

on two studies in which a CPM machine was used on 26 patients [37] and 31 patients respectively [28]. Both investigations compared physical therapy treatment (manual passive exercise) to the use of a CPM machine. Baumgarten et al. [3] concluded that the validity of the data is limited due to its poor methodological quality and provides insufficient evidence for the development of an evidence-based rehabilitation protocol. CPM treatment was not found to be superior. Du Plessis et al. [10] compared the effects of standard physical therapy to CPM therapy combined with physical therapy. The group of patients receiving CPM combined with physical therapy treatment, were given passive, isometric and actively supported exercises, shoulder mobilization and strength training. Manual passive mobilization, active exercise, and therapist coordinated self-exercise were used in the group that received standard physical training. Data on the range of movement, muscle strength, and pain reduction was collected, and studies previously conducted by Raab et al. [37] and Lastayo et al. [28], as well as a paper by Michael et al. [33] were also included. The authors of the review concluded that the use of a CPM machine in combination with physical therapy as part of follow-up treatment after an RCR can be regarded as safe [10]. A paper by Garofalo et al. [14] looked at 100 patients, comparing a standard program of passive exercise (therapist coordinated self-exercise: three series with 10 repetitions, pendulum movement, passive abduction, flexion and external rotation) to the same program with the addition of a CPM chair. This was applied for two hours a day for $4 \times 30 \mathrm{~min}$. In this comparison, the additional use of a CPM chair led to an improvement in results. It remains unclear, however, whether the device itself or the additional movement produced this effect [14]. 


\begin{tabular}{|c|c|c|c|c|c|}
\hline & $\begin{array}{l}\text { Appropriate } \\
(\%)\end{array}$ & $\begin{array}{l}\text { Rather } \\
\text { appropriate } \\
(\%)\end{array}$ & $\begin{array}{l}\text { Rather not } \\
\text { appropriate } \\
(\%)\end{array}$ & \multicolumn{2}{|c|}{$\begin{array}{l}\text { Not appropriate } \\
\text { (\%) }\end{array}$} \\
\hline $\begin{array}{l}\text { Question 1: } \\
\text { The use of self/home-exercises makes sense in the early }{ }^{\mathrm{a}} \text { post- } \\
\text { operative phase after RCR. } \\
\text { I consider this statement to be: }\end{array}$ & 36.4 & 20.5 & 22.7 & \multicolumn{2}{|l|}{20.5} \\
\hline $\begin{array}{l}\text { Question 2: } \\
\text { I hand out a post-operative exercise plan to the patient. } \\
\text { I consider this statement to be: }\end{array}$ & 38.6 & 18.2 & 9.1 & \multicolumn{2}{|l|}{34.1} \\
\hline $\begin{array}{l}\text { Question 3: } \\
\text { The initial instruction of self/home-exercises after a RCR by } \\
\text { a physiotherapist makes sense. } \\
\text { I consider this statement to be: }\end{array}$ & 68.2 & 27.3 & 4.5 & \multicolumn{2}{|c|}{0} \\
\hline $\begin{array}{l}\text { Question 4: } \\
\text { The visualization of self/home-exercises (by photo/video) } \\
\text { makes sense. } \\
\text { I consider this statement to be: }\end{array}$ & 59.1 & 29.5 & 6.8 & \multicolumn{2}{|l|}{4.5} \\
\hline $\begin{array}{l}\text { Question 5: } \\
\text { Self/home-exercises supersede physiotherapy units after RCR. } \\
\text { I consider this statement to be: }\end{array}$ & 9.1 & 11.4 & 40.9 & \multicolumn{2}{|l|}{38.6} \\
\hline \multirow{2}{*}{$\begin{array}{l}\text { Question 6: } \\
\text { The use of a continuous passive motion (CPM) device makes } \\
\text { sense during the post-operative treatment after RCR. } \\
\text { I consider this statement to be: }\end{array}$} & 22.7 & 13.6 & 34.1 & \multicolumn{2}{|l|}{29.5} \\
\hline & No CPM & $1 \times 30 \mathrm{~min}^{\mathrm{b}}$ & $2 \times 30 \mathrm{~min}^{\mathrm{b}}$ & $3 \times 30 \min ^{b}$ & $4 \times 30 \mathrm{~min}^{\mathrm{b}}$ \\
\hline $\begin{array}{l}\text { Question 7: } \\
\text { What is the frequency CPM therapy should be performed? }\end{array}$ & 56.8 & 4.5 & 18.2 & 13.6 & 6.8 \\
\hline
\end{tabular}

\section{Conclusions}

Based on these studies, no recommendation can be made with a high level of evidence for or against the use of CMP therapy following RCR, and not for the length of time, frequency and intensity of the CPM treatment. It should be noted, however, that passive motion exercise does not negatively impact the healing process (see - Table 7 for the DVSE expert opinions on CPM).

\section{Self-exercise}

In addition to CPM, self-exercise is another important component of post-operative follow-up treatment which is used to varying degrees $[8,11,18,29]$. There are major differences in point in time, intensity, type of exercise and supporting measures. Patients can be instructed through written directions, videos and/or receive instruction from the physiotherapist (PT). Roddey et al. [39] found there was no significant difference in the post- operative outcome when the instructions were given by the PT or by video.

Pendulum exercises were often described in the first post-operative phase. Biomechanical studies have shown that it is important to carry them out correctly so that there is low electromyographic activity (EMG) in the reconstructed RC (see below, [32]). The lowest activity was recorded in small pendulum circles $(\mathrm{d}=20 \mathrm{~cm})$ with an initiation of the arm movement by moving the torso and not by using the shoulder muscles themselves [32]. Additional use of a $1.5 \mathrm{~kg}$ weight on the hanging arm increases the EMG activity of M. supraspinatus and M. infraspinatus, though not to a statistically significant degree [12]. Furthermore, mobilization exercises (with the help of the contralateral arm) and, in later phases, muscle activation/strengthening exercises using simple devices (e.g. theraband, dumbbells) are other primary forms of selfexercise $[8,11,46]$. There is no homogeneous data on the extent of the passive mobilization and when to start it $[2,8$,
$21,29]$. The question of whether self-exercise, in addition to physiotherapy, has a positive effect cannot be sufficiently answered. Both are combined in many published studies, however a direct comparative study currently does not exist [1, 11, 31, 33, 46]. Scientific literature contains only two randomized controlled trials that look at self-exercise versus physiotherapy exercise [3]. In their Level II study, Hayes et al. [17] were able to randomize 58 patients into two control groups. After both groups received instructions on the self-exercise program in the first week, one group subsequently received physiotherapy treatment while the other group continued to do the selfexercise program. No significant differences in ROM, strength measurement and shoulder scores were found at any of the follow-up treatments $(6,12$ and 24 weeks). Critical aspects of the study include the low number of cases, the high conversion rate from the self-exercise group to the physiotherapy group $(n=9)$ and the high drop-out rate $(27 \%)$. 


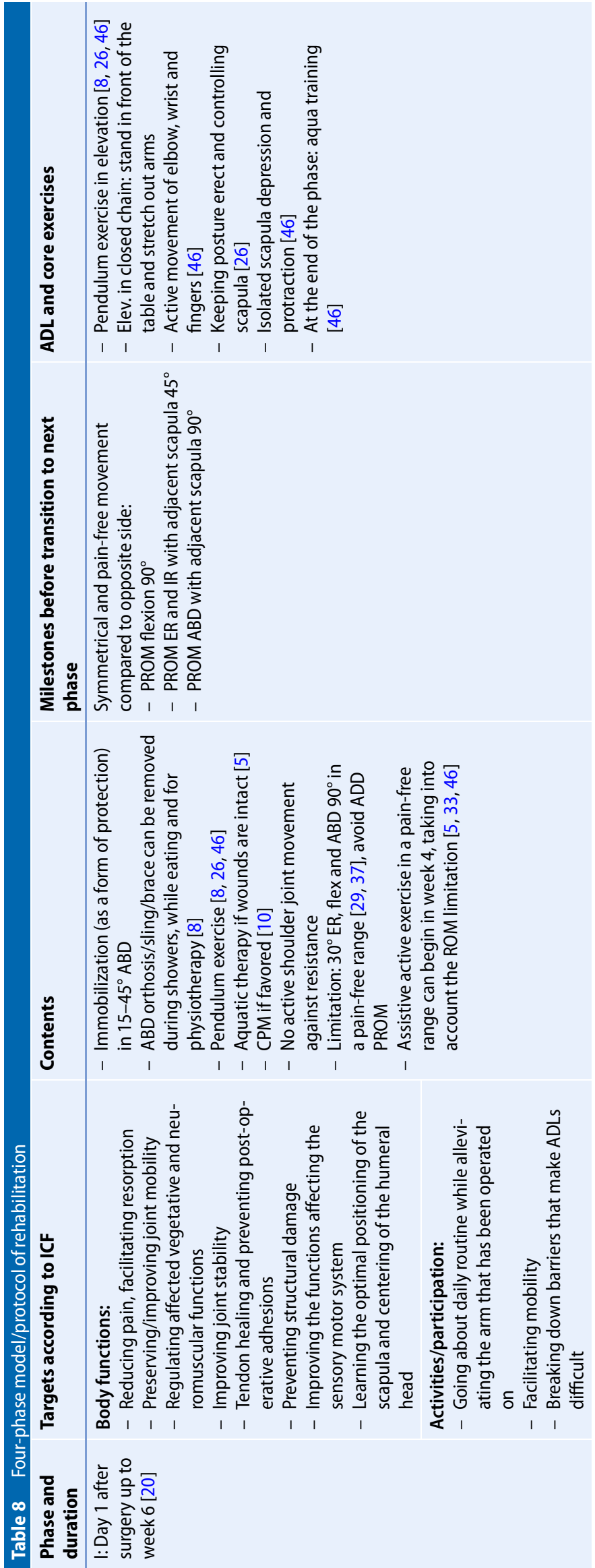

The second study by Lee et al. conducted a clinical and neurophysiological examination of 11 patients per group at days 20 and 40 post operation [29]. The results showed significantly better active mobility at both follow-ups in the group receiving physiotherapy. This group also achieved a significant improvement in the activation of motor units in the EMG; this was not detected in the self-exercise group. In this study the low number of cases, the short follow-up period and an absence of clinical scores should be viewed critically.

\section{Conclusions}

No Level I-based recommendation for or against the use of self-exercise can be made, however, based on the available studies, its use can be considered (see - Table 7 for DVSE expert opinions on self-exercise).

\section{Physiotherapy and the phase model}

\section{Rehabilitation phases/protocols (time- and criteria-based)}

In order to enable continuous progression of rehab-treatment, the post-operative process should be divided into different phases. The available literature usually breaks the process down into four phases. Thus, the different treatment focuses and the corresponding targets can be usefully classified $[23,27,40,44]$.

- The first phase is the time directly after the operation until week 6 .

During this time mainly passive and assistive exercises are conducted.

- This is followed by Phase 2 that lasts a further 6 weeks during which active functions are regained (week 7-12 post operation).

- Phase 3, strength building, starts in the third post-operative month (month 3 and 4).

- This is concluded by Phase 4 which includes the return to sports ( $\bullet$ Table 8 ; [20]).

The timeline is aligned with the general phases of wound healing and the time it takes for tissue to heal, as identified in an- 


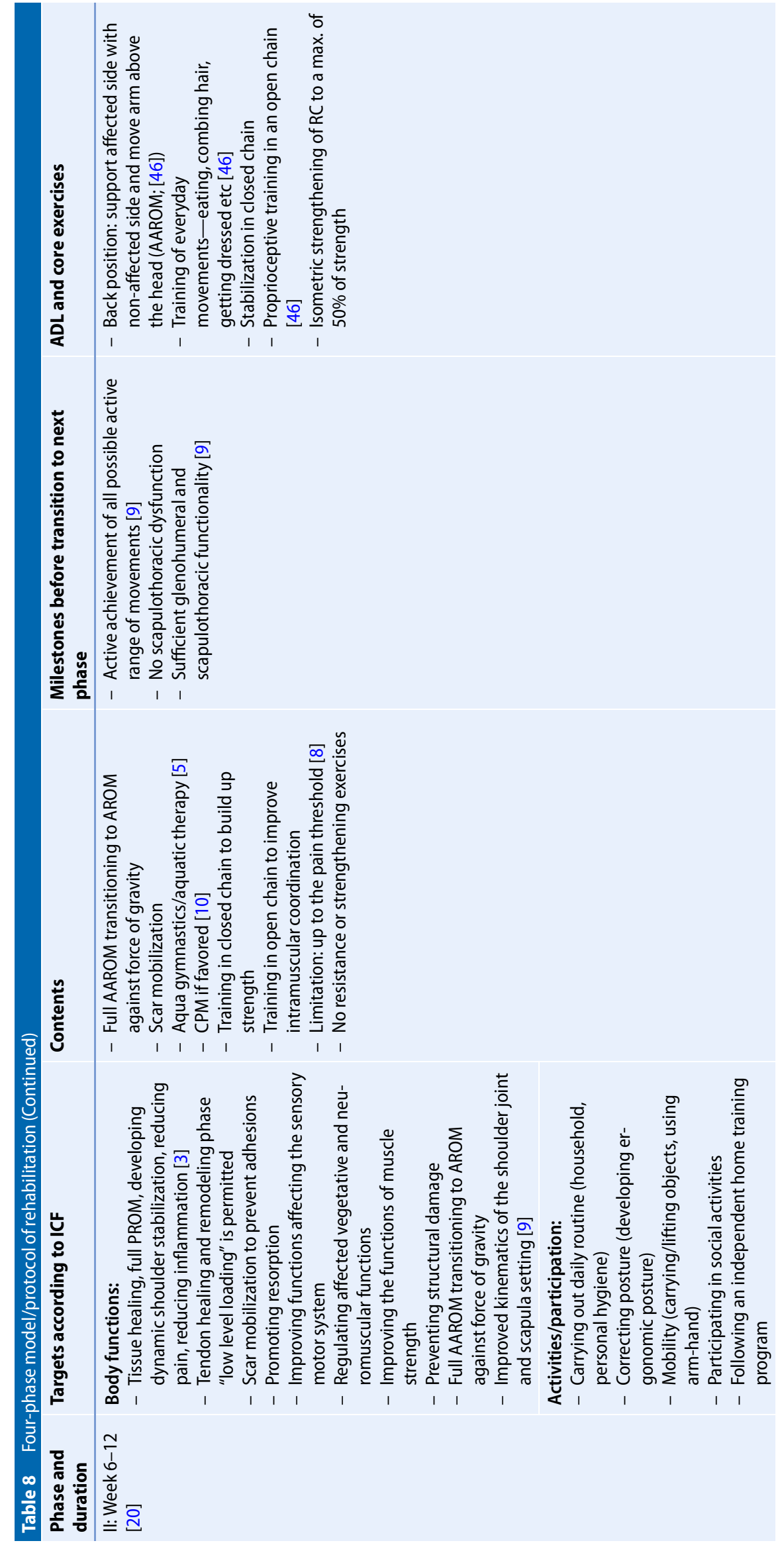




\section{Review}

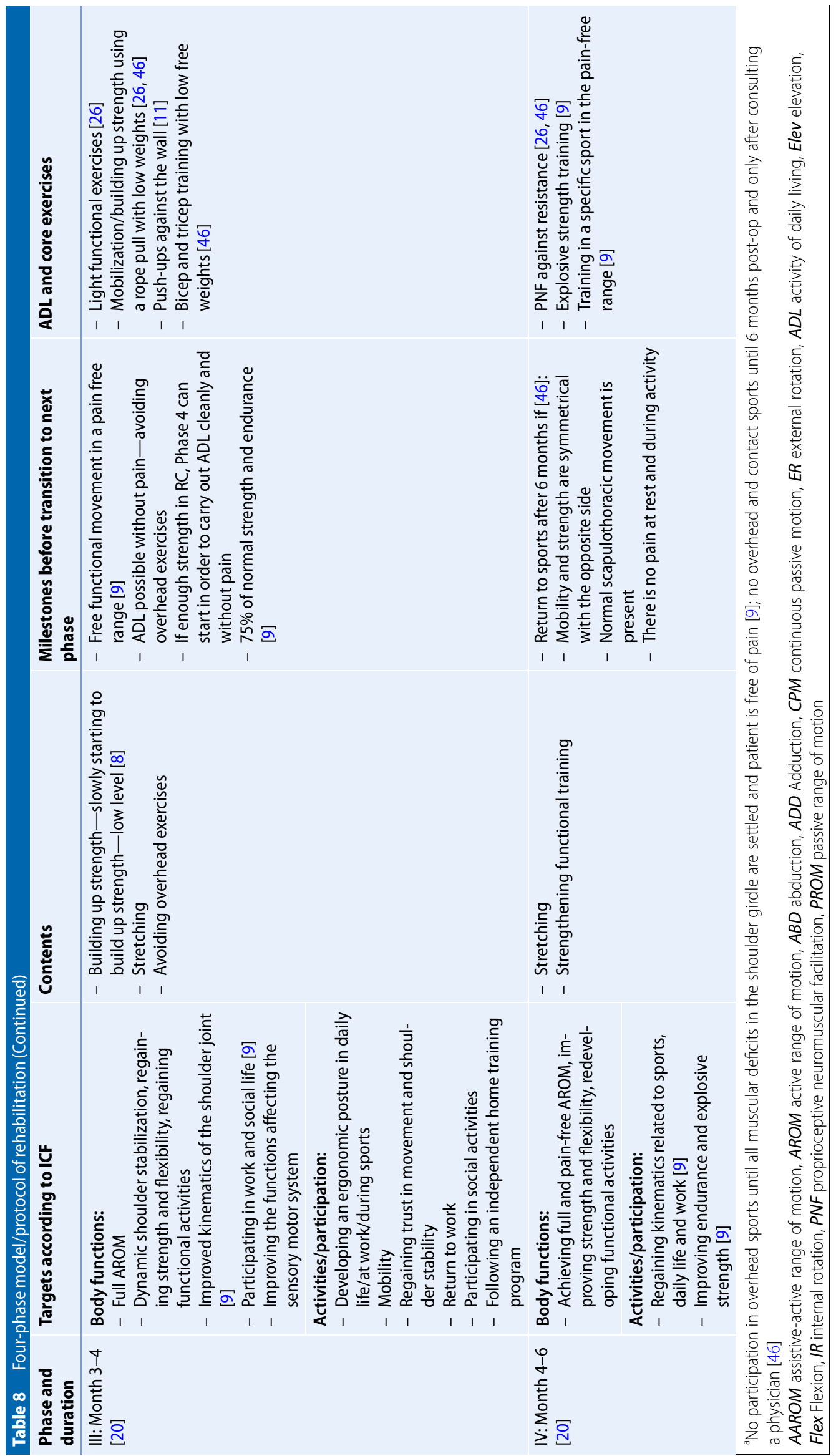




\begin{tabular}{|c|c|c|c|c|}
\hline & $\begin{array}{l}\text { Appropriate } \\
(\%)\end{array}$ & $\begin{array}{l}\text { Rather ap- } \\
\text { propriate } \\
\text { (\%) }\end{array}$ & $\begin{array}{l}\text { Rather not } \\
\text { appropri- } \\
\text { ate }(\%)\end{array}$ & $\begin{array}{l}\text { Not ap- } \\
\text { propriate } \\
(\%)\end{array}$ \\
\hline $\begin{array}{l}\text { Question 1: } \\
\text { The rehabilitation protocol after } \\
\text { RCR should has a progressive } \\
\text { exercise set-up and can be divided } \\
\text { into } 4 \text { phases. } \\
\text { I consider this statement to be: }\end{array}$ & 63.6 & 34.1 & 2.3 & 0 \\
\hline $\begin{array}{l}\text { Question 2: } \\
\text { The phase transitions and load } \\
\text { increases should be time-based } \\
\text { and criteria-based. } \\
\text { I consider this statement to be: }\end{array}$ & 81.8 & 18.2 & 0 & 0 \\
\hline
\end{tabular}

imal studies. These time markers define the framework for the follow-up treatment phases. There is a consensus that rehabilitation should be improved both in terms of time and criteria [9]. The literature defines no precise criteria that should act as the specific criteria which the patient should fulfil before moving on to the next rehabilitation phase. However, the "International Classification of Functioning, Disability and Health" (ICF) is a good basis for identifying targets. Orientational criteria are assigned to each phase as listed in - Table 8.

The four-phase model is structured as follows: Phase 1 lasts 6 weeks starting on the first day after the operation [20]. During this time, the key targets include achieving good tendon healing without post-operative adhesions and, above all, reducing pain for the patient. Throughout Phase 1 the shoulder should be immobilized in a position at $15-45^{\circ}$ abduction using an orthosis/sling/brace which is only taken off during physiotherapy and for hygiene purposes [8]. Only a passive exercise program is allowed until the end of the fourth week after the operation. Then, depending on the amount of pain the patient is still in, assistive exercise can be integrated into the treatment program $[5,33,46]$. Nevertheless, the extent of motion is limited to $30^{\circ}$ external rotation, $90^{\circ}$ flexion and abduction in a pain-free range $[29,37]$. Adduction should be avoided both in a passive and assistive fashion. The core exercises in this phase are pendulum and scapulathoracic exercises. All of the exercises to passively expand elevation are only allowed in a closed chain [1]. Only the exercising of the adjacent joints, elbow, hand and fingers is active and allowed in an open chain $[1,26,46]$. After 6 weeks and at the end of Phase 1 , a passive flexion up to $90^{\circ}$, a passive internal and external rotation with adjacent scapula up to $45^{\circ}$ and a passive abduction, also with an adjacent scapula up to $90^{\circ}$ on the operated side, should be possible. The movement should be symmetrical to the opposite side and pain free.

The activities of Phase 2 are done until week 12 following the operation. The goals of this phase include tissue healing, achieving a full passive range of movement and the development of dynamic shoulder stabilization. In this phase of tendon healing and remodeling, only "low level loading" is allowed. At the same time, scar mobilization is an important element to prevent adhesions. By the end of this phase, the full range of movement can be trained in an activeassistive fashion and an active increase in movement against the force of gravity can start. This targets the improvement of the kinematics of the shoulder joint [9].

Twelve weeks after the operation the patient should also actively achieve the degree of motion that was achieved passively up to this point in time. It should be noted that by now there should no longer be any scapulothoracic dysfunction [9]. Once there is sufficient glenohumeral and scapulothoracic movement, the therapy can move on to Phase 3 [9].

In Phase 3 (month 3 and 4 post operation) the full active range of movement and dynamic shoulder stabilization should be achieved. At this point in time, tendon healing should have progressed enough to integrate strengthening and stretching as additional elements in this phase so that patients can regain functional activity and participate in their professional and social lives [9]. Light functional exercises and mobilization/ strengthening exercises using a pulley with low weights are a good way to do this at this time [26, 46]. Push-ups against the wall $[5,11]$ and bicep and tricep exercises with low free weights or a resistance band are once again permitted [46].

At the end of post-operative month 4 the patient should have regained full functional movement within the painfree range and be able to perform activities of daily living (ADL) without pain [9]. At this point in time, around $75 \%$ of normal strength and endurance has been reestablished [9]. When there is sufficient strength in the RC to carry out ADL cleanly and without pain, Phase 4 can start. In the fourth and final phase, which extends up to 6 months after the operation, training focuses on maintaining a final and pain-free active range of movement, improving strength and flexibility, and improving endurance and explosive power [9]. Regaining functional activities and reestablishing kinematics related to sports, daily life and work are the aims of this final phase as defined by the ICF [9]. A return to sports isn't permitted until the end of this final phase and until mobility and strength are symmetrical with the opposite side. Further requirements are normal scapulothoracic mobility and no pain at rest and during activity ([46]; see 0 Table 7 and 9 for DVSE expert opinions on physiotherapy and the phase model).

\section{Conclusions for clinical practice}

Today, RCR is an established standard procedure. The post-operative followup treatment period is expected to be long and time-consuming. The contents and concepts of therapy are, thus, applied in different ways and controversially discussed. The number of publications on the subject is therefore high. Unfortunately, not all of the papers fulfil the required quality criteria of evidence-based medicine. 
Since 2004 one guideline, four reviews and 17 original papers have been identified that serve as the basis for establishing structured follow-up treatment. For some treatments, clear recommendations can be derived. These include early passive exercise, using cryotherapy to reduce the pain, self-exercise and the use of orthoses. Despite this, there are still questions that cannot be answered conclusively based on the available literature. When all of the results were looked at together, a basic concept that was solid and valid could nevertheless be created which was summarized in a four-phase model. The main points of this model were supported and supplemented for the first time through collected and pooled expert opinions from the DVSE expert society.

\section{Corresponding address}

\section{Dr. C. Jung}

Schulthess Klinik Zürich, Obere Extremitäten Lengghalde 2, 8008 Zürich, Switzerland christian.jung@kws.ch

\section{Compliance with ethical guidelines}

Conflict of interest. C. Jung, L. Tepohl, R. Tholen, K. Beitzel, S. Buchmann, T. Gottfried, C. Grim, B. Mauch, G. Krischak, H. Ortmann, C. Schoch and F. Mauch declare that they have no competing interests.

This article does not contain any studies with human participants or animals performed by any of the authors.

Open Access This article is distributed under the terms of the Creative Commons Attribution 4.0 International License (http://creativecommons.org/licenses/by/ 4.0/), which permits unrestricted use, distribution, and reproduction in any medium, provided you give appropriate credit to the original author(s) and the source, provide a link to the Creative Commons license, and indicate if changes were made.

\section{References}

1. Alenabi T, Jackson M, Tetreault P et al (2013) Electromyographic activity in the immobilized shoulder musculature during ipsilateral elbow, wrist, and finger movements while wearing a shoulder orthosis. J Shoulder Elbow Surg 22:1400-1407

2. Arndt J, Clavert P, Mielcarek P et al (2012) Immediate passive motion versus immobilization after endoscopic supraspinatus tendon repair: a prospective randomized study. Orthop Traumatol Surg Res 98:S131-S138

3. Baumgarten KM, Vidal AF, Wright RW (2009) Rotator cuff repair rehabilitation: a level I and II systematic review. Sports Health 1:125-130

4. Blum K, Chen AL, Chen TJ et al (2009) Repetitive $\mathrm{H}$-wave device stimulation and program induces significant increases in the range of motion of post operative rotator cuff reconstruction in a doubleblinded randomized placebo controlled human study. BMC Musculoskelet Disord 10:132

5. Brady B, Redfern J, Macdougal G et al (2008) The addition of aquatic therapy to rehabilitation following surgical rotator cuff repair: a feasibility study. Physiother Res Int 13:153-161

6. Chan K, Macdermid JC, Hoppe DJ et al (2014) Delayed versus early motion after arthroscopic rotator cuff repair: a meta-analysis. J Shoulder Elbow Surg 23:1631-1639

7. Conti M, Garofalo R, Delle Rose G et al (2009) Postoperative rehabilitation after surgical repair of the rotator cuff. Chir Organi Mov 93(Suppl 1):S55-S63

8. CuffDJ, PupelloDR (2012) Prospective randomized study of arthroscopic rotator cuff repair using an early versus delayed postoperative physical therapy protocol. J Shoulder Elbow Surg 21:1450-1455

9. Dreinhofer KE, Schuler S, Schafer M et al (2014) Rehabilitation concepts and return to sport after interventions on the shoulder. Orthopäde 43:256-264

10. Du Plessis M, Eksteen E, Jenneker A et al (2011) The effectiveness of continuous passive motion on range of motion, pain and muscle strength following rotator cuff repair: a systematic review. Clin Rehabil 25:291-302

11. Duzgun I, Baltaci G, Atay OA (2011) Comparison of slow and accelerated rehabilitation protocol after arthroscopic rotator cuff repair: pain and functional activity. Acta Orthop Traumatol Turc 45:23-33

12. Ellsworth AA, Mullaney M, Tyler TF et al (2006) Electromyography of selected shoulder musculature during un-weighted and weighted pendulum exercises. N Am J Sports Phys Ther 1:73-79

13. Galatz LM, Charlton N, Das R et al (2009) Complete removal of load is detrimental to rotator cuff healing. J Shoulder Elbow Surg 18:669-675

14. Garofalo R, Conti M, Notarnicola A et al (2010) Effects of one-month continuous passive motion after arthroscopic rotator cuff repair: results at 1-year follow-up of a prospective randomized study. Musculoskelet Surg 94(Suppl 1):S79-S83

15. Gerber C, Schneeberger AG, Perren SM et al (1999) Experimental rotator cuff repair. A preliminary study. J Bone Joint Surg Am 81:1281-1290

16. Gimbel JA, Van Kleunen JP, Williams GR et al (2007) Long durations of immobilization in the rat result in enhanced mechanical properties of the healing supraspinatus tendon insertion site. J Biomech Eng 129:400-404

17. Hayes K, Ginn KA, Walton JR et al (2004) A randomised clinical trial evaluating the efficacy of physiotherapy after rotator cuff repair. Aust J Physiother 50:77-83

18. Holmgren T, Oberg B, Sjoberg I et al (2012) Supervised strengthening exercises versus homebased movement exercises after arthroscopic acromioplasty: a randomized clinical trial. JRehabil Med 44:12-18

19. Hultenheim Klintberg I, Gunnarsson AC, Styf J et al (2008) Early activation or a more protective regime after arthroscopic subacromial decompression-a description of clinical changes with two different physiotherapy treatment protocols-a prospec tive, randomized pilot study with a two-year follow-up. Clin Rehabil 22:951-965

20. Keener JD, Galatz LM, Stobbs-Cucchi G et al (2014) Rehabilitation following arthroscopic rotator cuff repair: a prospective randomized trial of immobilization compared with early motion. JBone Joint Surg Am 96:11-19

21. Kim JY, Lee JS, Park CW (2012) Extracorporeal shock wave therapy is not useful after arthroscopic rotator cuff repair. Knee Surg Sports Traumatol Arthrosc 20:2567-2572

22. Kim YS, Chung SW, Kim JY et al (2012) Is early passive motion exercise necessary after arthroscopic rotator cuff repair? Am J Sports Med 40:815-821

23. Korsukéwitz C (2008) Evidenz und Qualität in der Rehabilitation: Die Leitlinien der Deutschen Rentenversicherung. In: Bund DR (ed) 17. Rehabilitations-wissenschaftliches Kolloquium. Bremen, pp 31-32

24. Korsukewitz C, Rose S, Schliehe F (2003) The significance of clinical guidelines for rehabilitation. Rehabilitation (Stuttg) 42:67-73

25. Korsukéwitz CRS, Schliehe F (2003) Zur Bedeutung von Leitlinien für die Rehabilitation. Rehabilitation (Stuttg) 42:67-73

26. Krischak G, Gebhard F, Reichel H et al (2013) A prospective randomized controlled trial comparing occupational therapy with home-based exercises in conservative treatment of rotator cuff tears. J Shoulder Elbow Surg 22:1173-1179

27. Lapner PL, Sabri E, Rakhra K et al (2012) A multicenter randomized controlled trial comparing single-row with double-row fixation in arthroscopic rotator cuff repair. J Bone Joint Surg Am 94:1249-1257

28. Lastayo PC, Wright T, Jaffe Ret al (1998) Continuous passive motion after repair of the rotator cuff. A prospective outcome study. J Bone Joint Surg Am 80:1002-1011

29. Lee BG, Cho NS, Rhee YG (2012) Effect of two rehabilitation protocols on range of motion and healing rates after arthroscopic rotator cuff repair: aggressive versus limited early passive exercises. Arthroscopy 28:34-42

30. Li S, Min SX, Zhang $\mathrm{H}$ et al (2010) Effect of continuous passive motion on basic fibroblast growth factor expression during tendon-bone repair after surgical repair of acute rupture of the supraspinatus tendon in rabbits. J South Med Univ 30:1020-1023

31. Lisinski P, Huber J, Wilkosz P et al (2012) Supervised versus uncontrolled rehabilitation of patients after rotator cuff repair-clinical and neurophysiological comparative study. Int J ArtifOrgans 35:45-54

32. Long JL, Ruberte Thiele RA, Skendzel JG et al (2010) Activation of the shoulder musculature during pendulum exercises and light activities. J Orthop Sports Phys Ther 40:230-237

33. Michael JW, Konig DP, Imhoff $A B$ et al (2005) Efficiency of a postoperative treatment after rotator cuff repair with a continuous passive motion device (CPM). Z Orthop Ihre Grenzgeb 143:438-445

34. Oh CH, Oh JH, Kim SH et al (2011) Effectiveness of subacromial anti-adhesive agent injection after arthroscopic rotator cuff repair: prospective randomized comparison study. Clin Orthop Surg 3:55-61

35. Osbahr DC, Cawley PW, Speer KP (2002) The effect of continuous cryotherapy on glenohumeral joint and subacromial space temperatures in the postoperative shoulder. Arthroscopy 18:748-754 
36. Peltz CD, Dourte LM, Kuntz AF et al (2009) The effect of postoperative passive motion on rotator cuff healing in a rat model. J Bone Joint Surg Am 91:2421-2429

37. RaabMG, Rzeszutko D, O'connorWetal (1996) Early results of continuous passive motion after rotator cuff repair: a prospective, randomized, blinded, controlled study. Am J Orthop (Belle Mead, NJ) 25:214-220

38. Rathbun JB, Macnab I (1970) The microvascular pattern of the rotator cuff. J Bone Joint Surg Br 52:540-553

39. Roddey TS, Olson SL, Gartsman GM et al (2002) A randomized controlled trial comparing 2 instructional approaches to home exercise instruction following arthroscopic full-thickness rotator cuff repair surgery. J Orthop Sports Phys Ther 32:548-559

40. Ross D, Maerz T, Lynch J et al (2014) Rehabilitation following arthroscopic rotator cuff repair: a review of current literature. J Am Acad Orthop Surg 22:1-9

41. Shen C, Tang ZH, Hu JZ et al (2014) Does immobilization after arthroscopic rotator cuff repair increase tendon healing? A systematic review and meta-analysis. Arch Orthop Trauma Surg 134:1279-1285

42. Singh $H$, Osbahr DC, Holovacs TF et al (2001) The efficacy of continuous cryotherapy on the postoperative shoulder: a prospective, randomized investigation. J Shoulder Elbow Surg 10:522-525

43. Speer KP, Warren RF, Horowitz L (1996) The efficacy of cryotherapy in the postoperative shoulder. JShoulder Elbow Surg 5:62-68

44. Tashjian RZ (2012) Epidemiology, natural history, and indications for treatment of rotator cuff tears. Clin Sports Med 31:589-604

45. Thomopoulos S, Williams GR, Soslowsky LJ (2003) Tendon to bone healing: differences in biomechanical, structural, and compositional properties due to a range of activity levels. JBiomech Eng 125:106-113

46. Van Der Meijden OA, Westgard P, Chandler Z et al (2012) Rehabilitation after arthroscopic rotator cuff repair: current concepts review and evidencebased guidelines. Int J Sports Phys Ther 7:197-218

47. Zhang S, Li H, Tao H et al (2013) Delayed early passive motion is harmless to shoulder rotator cuff healing in a rabbit model. Am J Sports Med 41:1885-1892 